\title{
Fast orthograde axonal transport in sciatic motoneurones and nerve temperature in streptozotocin-diabetic rats
}

\author{
S. J. Whiteley, J. Townsend, D. R. Tomlinson and A. M. Brown \\ Department of Physiology and Pharmacology, Medical School, Queen's Medical Centre, Nottingham, UK
}

\begin{abstract}
Summary. This study measured the velocity of fast orthograde axonal transport of incorporated ${ }^{3} \mathrm{H}$-proline in motoneurones of the sciatic nerve in control rats and in rats with streptozotocin-induced diabetes of 3 weeks duration. Sciatic nerve and abdominal cavity temperatures were monitored throughout the period of measurement of transport velocity, and the rats were warmed to minimise hypothermia at both sites. There was marked abdominal and sciatic nerve hypothermia immediately after operation, and this effect was more intense in diabetic rats than in control rats. In steady state, abdominal cavity temperature (mean $\pm \mathrm{SEM}$ ) was $38.1 \pm 0.1^{\circ} \mathrm{C}$ in both control and diabetic rats, and the sciatic nerve temperatures were $37.8 \pm 0.1^{\circ} \mathrm{C}$ in controls and $37.1 \pm 0.3{ }^{\circ} \mathrm{C}$ in diabetic rats. The
\end{abstract}

difference was not statistically significant. The velocities of orthograde axonal transport for the fastest molecules containing ${ }^{3} \mathrm{H}$-proline were $14.0 \pm 0.9$ (SEM)mm/ $\mathrm{h}$ for controls and $13.9 \pm 1.1(\mathrm{SEM}) \mathrm{mm} / \mathrm{h}$ for diabetic rats. Thus, no velocity difference was observed. The findings are discussed in relation to measurements of fast orthograde transport velocity in experimental diabetes in other studies. It is suggested that, where velocity deficits have been seen in diabetic rats, nerve hypothermia should be considered as a contributory factor.

Key words: Axonal flow, diabetic neuropathies, hypothermia, motor neurones, streptozotocin-diabetes.
The extremities of peripheral neurones are dependent for survival on the delivery, by orthograde axonal transport, of components of axoplasm which originate in the cell body. Experimental interruption of this transport leads to axonal degeneration and failure of synaptic contact with the target cell [1]. There have been several studies which have examined the competence of fast orthograde axonal transport in experimental diabetes to test the premise that failure of this transport process may contribute to experimental diabetic neuropathy. There is controversy over the existence of defects of fast orthograde axonal transport in diabetic rodents. Studies on the process in sciatic dorsal root afferents in streptozotocin-diabetic rats $[2,3]$ and in vagal afferents in alloxan-diabetic rabbits [4] reported no defects in velocity of transport. Another study described reduced velocity in sciatic motoneurones of streptozotocin-diabetic rats, a deficit which was prevented by twice-daily insulin [5]. Finally, a study using BB Wistar rats reported a velocity deficit for fast transport in sciatic sensory neurones in both hyperglycaemic and hypoglycaemic (induced by exaggerated insulin treatment) diabetic animals [6].

Fast axonal transport velocity decreases with decreasing nerve temperature $[7,8]$. The studies on diabet- ic rats referred to above used neurones which have axons in the sciatic nerve. The profound wasting of skeletal muscle in uncontrolled experimental diabetes reduces the thermal insulation of the sciatic nerve for much of its length. It is therefore possible that the axons of sciatic neurones become hypothermic due to muscle wasting in rats with experimental diabetes, and that in some studies this has contributed to observed defects of fast axonal transport. The object of this study was to measure the velocity of fast transport of proteins synthesised in the cell bodies of sciatic motoneurones under conditions which resulted in similar sciatic nerve temperatures in control and diabetic rats.

\section{Materials and methods}

\section{Animals and induction and monitoring of diabetes}

Male Wistar rats (weight range 345-360 g, age 18-19wk), obtained from the Joint Animal Breeding Unit, University of Nottingham School of Agriculture, were allocated at random to two groups. The rats of one group were given streptozotocin (ICI Pharmaceuticals Division, Alderley Park, Macclesfield, England) at a dose of $50 \mathrm{mg} / \mathrm{kg}$ intraperitoneally after an overnight fast. Control rats were given an 


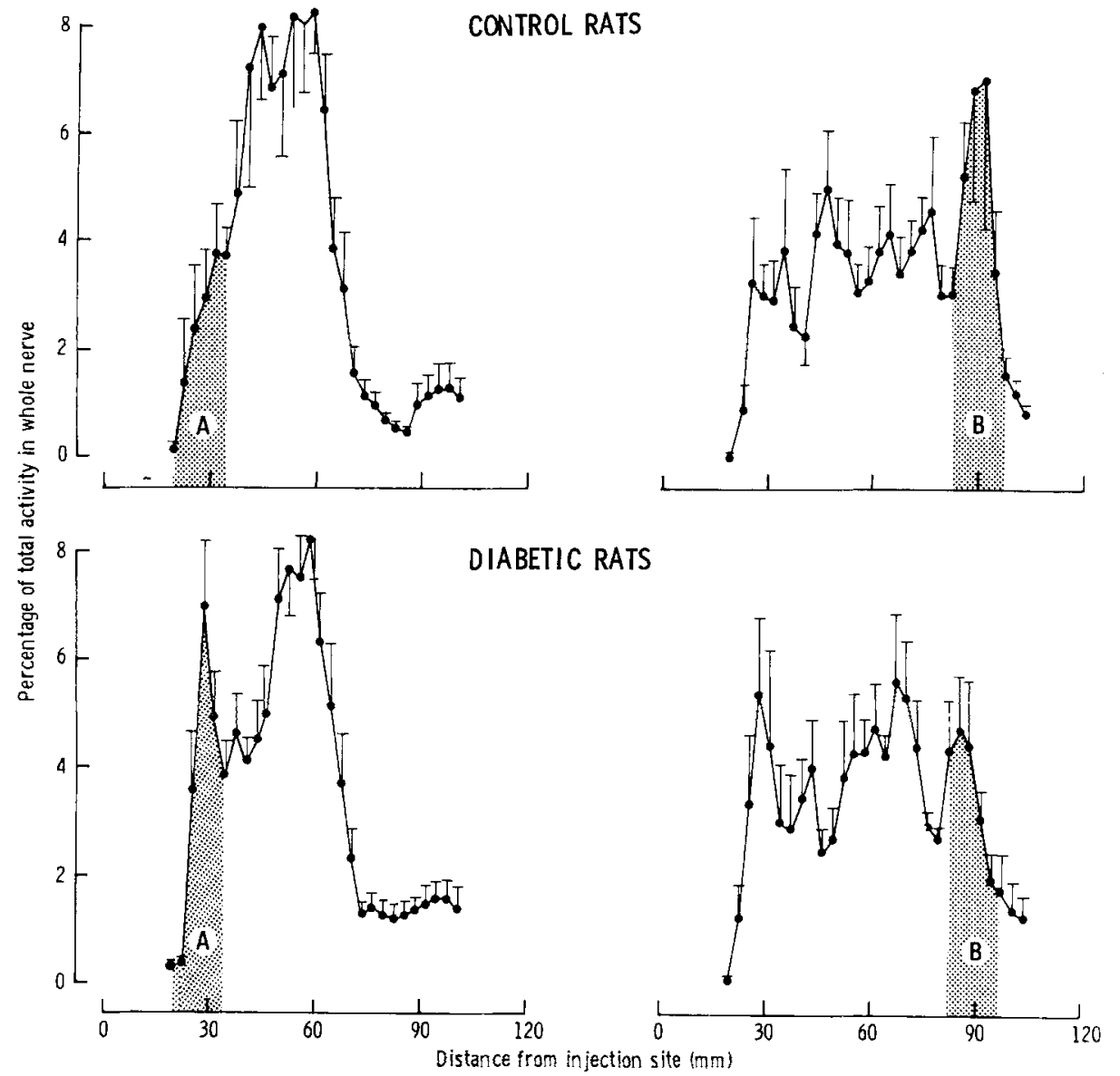

Fig. 1. Profiles showing the distribution of radioactivity along the sciatic nerves of control and diabetic rats allowed to survive for either $4.5 \mathrm{~h}$ (left hand profiles) or $6.5 \mathrm{~h}$ (right hand profiles) after injection of ${ }^{3} \mathrm{H}$-proline into the ventral horn of the spinal cord at $\mathrm{L}_{1}$. The significance of stippled areas $A$ and $B$ is explained in text. Limit bars denote SEM. The number of rats per group is given in Table 1 equivalent volume of $\mathrm{NaCl}(154 \mathrm{mmol} / \mathrm{l})$. Three days later a blood sample, obtained by tail prick from the streptozotocin-treated rats, was screened for glucose by a glucose oxidase strip-operated reflectance meter (Reflomat, Boehringer Ingelheim Corporation, London, England). Rats with blood glucose values of less than $15 \mathrm{mmol} / 1$ were rejected from the study. Axonal transport and nerve temperature were measured 21 days after the start of the experiment. These measurements were made on mixed groups so that diabetic rats were processed alongside controls on the same day.

\section{Axonal transport measurements}

Rats were anaesthetised with halothane ( $5 \%$ in $\mathrm{O}_{2}$ for induction, 1-2\% in $\mathrm{O}_{2}$ for maintenance), and laminectomies were performed at the $\mathrm{L}_{1}$ vertebra. A glass micropipette (tip diamter $10-15 \mu \mathrm{m}$ ) was inserted into the ventral horn of the spinal cord first on one side and then on the other. With each insertion, two injections of $1 \mu \mathrm{L} \mathrm{L}-\left(2,3,4,5-{ }^{3} \mathrm{H}\right)$-proline (specific activity $108 \mathrm{Ci} / \mathrm{mmol}$; Amersham International plc, Amersham, Buckingshamshire, England) were made. The total activity injected per rat was $30 \mu \mathrm{Ci}$. The isotope was prepared freshly each day by freeze drying the manufacturer's solution and redissolving it in more concentrated form in $\mathrm{NaCl}(154 \mathrm{mmol} / \mathrm{l})$. Immediately after spinal cord injection, thermocouples were inserted for temperature measurement.

Rats were allowed to survive for either 4.5 or $6.5 \mathrm{~h}$ after ventral horn injection. They were anaesthetised with halothane, bled from the heart, and both sciatic nerves were removed within $5 \mathrm{~min}$ and placed on an ice-cold stainless steel plate to arrest transport. The nerves were then frozen under modest tension on a brass block cooled with liquid $\mathrm{N}_{2}$ and cut into $3 \mathrm{~mm}$ segments, with segment 1 being the $\mathrm{L}_{4}$ dorsal root ganglion. The distance from this ganglion to the injection site was measured on the cadaver with dividers, and used later to calculate the distance travelled by the front of radioactivity. Each nerve segment was placed in $1 \mathrm{ml}$ trichloroacetic acid (10\%w:v) for $24 \mathrm{~h}$ at $4{ }^{\circ} \mathrm{C}$ to precipitate the proteins and to remove the unincorporated isotope. Supernatants were discarded, and the precipitates were dissolved in $150 \mu \mathrm{l}$ alkaline tissue solubilizer (NCS, Amersham Corporation, Illinois, USA) for $2 \mathrm{~h}$ at $60^{\circ} \mathrm{C}$. Three $\mathrm{ml}$ scintillation fluid (Fisofluor: Fisons Scientific Apparatus, Loughborough, England) were added, and the radioactivity was measured by liquid scintillation counting (CD 300, Packard Instrument Co. Inc., Illinois, USA).

\section{Temperature measurements}

Immediately after injection of the spinal cord, a thermocouple (tip diameter $1 \mathrm{~mm}$ Comark Electronics Ltd., Littlehampton, England) was sutured to the muscle adjacent to the left sciatic nerve level with the midpoint of the femur. The thermocouple was inserted via a small incision over the sciatic notch so that the wound was about $2 \mathrm{~cm}$ proximal to the position of the thermocouple tip. This was done to minimise the influence of abnormal heat exchange at the site of the wound. The muscle and fascia were closed with suture thread and the skin with Michel clips. A second thermocouple was inserted into the abdominal cavity rostral to the right kidney. This gave a measurement which was judged to be close to body core temperature. Both thermocouple leads were exteriorised at the back of the neck and passed through a perspex block into a flexible steel spring. The perspex block was attached to the rat by means of a small harness. This arrangement permitted the animal freedom of movement whilst protecting the thermocouple leads. Finally the incision over the $\mathrm{L}_{1}$ laminectomy was closed with Michel clips and the rat transferred to an open box under an infra-red lamp. Part of the box was shaded from the lamp so that the rat could move away from the heart source. The thermocouples were connected to an electronic microprocessor thermometer $(\mathrm{Co}-$ mark Electronics Ltd., Littlehampton, England) which gave 2 min read-out from each thermocouple in sequence. We therefore obtained 
a measurement of sciatic nerve and abdominal cavity temperature for each rat at intervals of 10 to $15 \mathrm{~min}$ (depending upon the number of thermocouples connected) throughout the course of the experiment.

\section{Processing of axonal transport data}

The radioactivity in each sample was converted to dpm by interpolation on a standard quench curve using a microcomputer [9]. The levels of radioactivity in each nerve varied within and between animals. To permit data grouping, the activity (as dpm) in each segment was calculated as a percentage of the total activity in the whole nerve. A profile of the distribution of activity (ordinate) was plotted with the distance from the injection site (at $3 \mathrm{~mm}$ intervals) as the abscissa. The activity profile contained peaks and troughs, especially $6.5 \mathrm{~h}$ after injection. The most distal peak was immediately proximal to a steep decay in activity (Fig. 1). We defined this steep decay in activity as the transport front. The front was calculated by linear regression, and the baseline by taking the mean activity of all segments distal to the front. This gave a point of intersection between front and baseline whose position gave the distance travelled by the fastest labelled material. The distance of this point and that of the peak from the injection site were defined respectively as the peak front distance and the peak distance. These variables were calculated for each nerve, and the arithmetic means of the values for left and right nerves were calculated for each rat. The diabetic and control groups each contained rats which had survived for 4.5 and $6.5 \mathrm{~h}$ after injection. Mean peak and peak front distances were calculated for each group at each survival time. The mean peak and peak front velocities over the final $2 \mathrm{~h}$ were then calculated from the mean $4.5 \mathrm{~h}$ and $6.5 \mathrm{~h}$ distances and expressed as

Table 1. Peak and peak front distances and axonal transport velocities calculated from the distance separating the $4.5 \mathrm{~h}$ and $6.5 \mathrm{~h}$ fronts and expressed as mm/h. $n=$ number of rats in each condition. Values are mean \pm SEM. There were no significant differences between control rats and diabetic rats

\begin{tabular}{llll}
\hline & \multicolumn{2}{l}{$\begin{array}{l}\text { Distance travelled from injection } \\
\text { site }(\mathrm{mm})\end{array}$} & $\begin{array}{l}\text { Axonal } \\
\text { transport } \\
(\mathrm{mm} / \mathrm{h})\end{array}$ \\
\cline { 2 - 3 } & $\begin{array}{l}4.5 \mathrm{~h} \text { after } \\
\text { injection }\end{array}$ & $\begin{array}{l}6.5 \mathrm{~h} \text { after } \\
\text { injection }\end{array}$ & \\
\hline Control rats & $(n=6)$ & $(n=7)$ & \\
$\quad \begin{array}{l}\text { Peak } \\
\text { Peak front }\end{array}$ & $70.7 \pm 1.7$ & $89.9 \pm 0.7$ & $14.1 \pm 0.9$ \\
Diabetic rats & $(n=10)$ & $98.8 \pm 0.6$ & $14.0 \pm 0.9$ \\
Peak & $60.7 \pm 1.8$ & $(n=7)$ & \\
Peak front & $71.0 \pm 1.6$ & $98.3 \pm 2.0$ & $14.3 \pm 1.4$ \\
\hline
\end{tabular}

$\mathrm{mm} / \mathrm{h}$. The time taken for uptake and incorporation of the isotope was assumed to be similar for both survival times, so that this procedure gave a velocity measurement which was unaffected by these stages in the process. The SE of the difference between the $4.5 \mathrm{~h}$ and $6.5 \mathrm{~h}$ mean front distances was calculated from the mean values and their SEM, as described elsewhere [10], to obtain a SEM for the distance travelled between $4.5 \mathrm{~h}$ and $6.5 \mathrm{~h}$ after injection and hence for transport velocity. All data are expressed as mean \pm SEM. Except where stated otherwise, significance of differences between means was estimated by unpaired Student's t-tests. A value for $2 p$ of less than 0.05 was taken to indicate statistical significance.

To compose mean profiles of the distribution of radioactivity along the nerve, the arithmetic means \pm SEM of the $\%$ total activity in each segment were calculated for each of the survival times in both groups. Before this, the segmental values ( $\%$ total $\mathrm{dpm}$ ) for the left and right nerves of each rat were averaged so that for the group data $n$ was the number of rats and not the number of nerves.

Examination of the group profiles indicated some differences between diabetic and control rats in the relative positions of sub-peaks within the profiles. The significance of these differences was examined by computing the percentage fraction of the total activity present in a defined segment of nerve for each rat. This is indicated by the stippled area encompassing the peaks labelled A and B in Figure 1. The percentage fractions contributing to sub-peaks were compared between groups using Mann Whitney U-tests because we had no basis for assuming normality of distribution of these variables.

\section{Results}

\section{Blood glucose}

At death the control rats had blood glucose levels of $4.5 \pm 0.1$ ( $4.5 \mathrm{~h}$ group) and $4.6 \pm 0.4(6.5 \mathrm{~h}$ group) $\mathrm{mmol} / \mathrm{l}$. The values for the diabetic rats were $19.6 \pm 1.6$ ( $4.5 \mathrm{~h}$ group) and $17.1 \pm 1.3(6.5 \mathrm{~h}$ group) $\mathrm{mmol} / \mathrm{l}$.

\section{Axonal transport}

The four grouped profiles describing the distribution of activity along the nerve are shown in Figure 1, and the velocities and distances are given in Table 1 . These data show that there were no significant differences in either peak distance or in peak front distance between diabetic and control rats at either survival time. Accordingly,

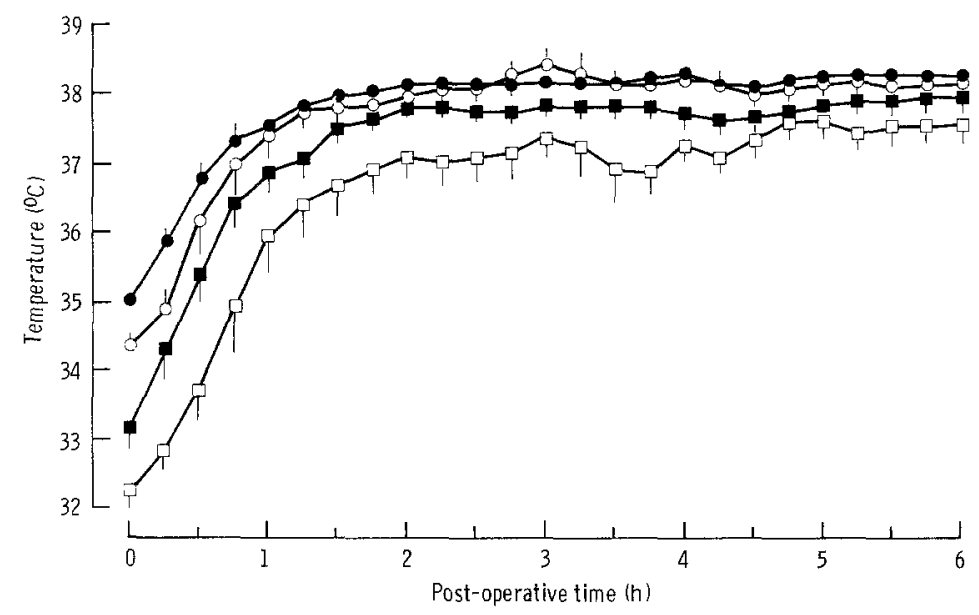

Fig. 2. Temperature profiles for sciatic nerve at mid-femur level (squares) and for abdominal cavity (circles) in control (filled symbols) and diabetic (open symbols) rats. Onset ( $\mathrm{t}_{\mathrm{o}}$ ) was wound closure and removal from the halothane source 
the calculated velocities for the peaks and peak fronts were also similar in both groups of rats.

Examination of the group profile of radioactivity for the $4.5 \mathrm{~h}$ survival diabetic rats indicated the presence of a distinct sub-peak at approximately $30 \mathrm{~mm}$ distal to the injection site (see Fig. 1). Indeed, this sub-peak was present in all the nerves from this diabetic group. It was, however, absent from all controls at the same survival time. Comparison of the fraction of the total activity present in the 6 nerve segments encompassing this peak (Fig.1, stippled area A) indicated a significant difference between diabetic and control rats at $4.5 \mathrm{~h}$ survival $(2 p<0.05)$. The activity fractions present in the 6 segments comprising the fastest peak were compared, for diabetic and control groups, at $6.5 \mathrm{~h}$ survival (Fig.1, stippled area B). No significant difference was found.

\section{Temperature measurements}

Recovery of consciousness was brisk. All rats were ambulatory by $15 \mathrm{~min}$ after removal of the halothane source. In spite of this, core and sciatic nerve hypothermia persisted for at least an hour after return of consciousness. The data from the animals which survived for $6.5 \mathrm{~h}$ is shown in Figure 2. The data from the $4.5 \mathrm{~h}$ survivors was virtually identical and has not been included. In the diabetic rats, return of abdominal temperature to steady state after anaesthesia was slower than in the controls, though the final steady state temperatures were not different $\left(37.8 \pm 0.1^{\circ} \mathrm{C}\right.$ for both). The sciatic nerve temperatures of the diabetic rats also lagged behind the controls during post-operative recovery. In steady state, the nerves of the diabetic rats $\left(37.1 \pm 0.3^{\circ} \mathrm{C}\right)$ were not significantly cooler than those of the controls ( $37.8 \pm 0.1^{\circ} \mathrm{C}$, Fig. 2.).

\section{Anaesthetic effects}

In the Discussion we have stated that the values given above for axonal transport velocity in control rats are lower than those reported in other studies. One difference between our procedures and those of others was our use of halothane as an anaesthetic. We therefore performed similar experiments on 4 control rats using instead the short-acting barbiturate sodium methylhexitone and measured an orthograde fast transport velocity of $12.4 \pm 1.1 \mathrm{~mm} / \mathrm{h}$ with similar steady state nerve and abdominal temperatures. Thus, we have no indication that the use of halothane slows orthograde axonal transport.

\section{Discussion}

The results here show that, in 3-week diabetic rats under the experimental conditions employed, there was no deficit in the velocity of orthograde axonal transport of radiolabelled proteins in sciatic motoneurones. There was post-anaesthetic hypothermia of the sciatic nerve in all rats and this was more pronounced in the diabetic groups. However, in steady state - from 4.5 to $6 \mathrm{~h}$, when the measurement of axonal transport velocity was made - there was no difference in sciatic nerve temperature between diabetic and control rats. Absence of a deficit in transport velocity agrees well with findings in sensory neurones in rats of the same strain and sex $[2,3]$. However, it is at variance with findings of Meiri and McLean [5] of a significant $15 \%$ reduction in velocity of fast orthograde protein transport in sciatic motoneurones from female Sprague-Dawley rats anaesthetised with pentobarbital. While the differences in sex, strain and anaesthetic may explain the different results of these two studies, an alternative possibility suggested by the data of Figure 2 is that the deficit in transport velocity in diabetic rats observed by Meiri and McLean may reflect differences in nerve temperature. Figure 2 shows that although both sciatic nerve and body temperatures were similar in control and diabetic rats in steady state, nerve temperature was lower immediately after anaesthesia and took longer to return to steady state in the diabetic rats than in the controls. Pentobarbital produces a longer lasting anaesthesia than halothane, and, in addition, Meiri and McLean [5] began their axonal transport studies only $3.5 \mathrm{~h}$ after operation. It seems possible, therefore, that for part, if not all, of their experiment, nerve temperature may have been lower in the diabetic rats than in the controls, leading to a reduced transport velocity. This might also explain the apparent increase in the time taken for uptake and incorporation of isotope observed in diabetic rats in that study [5]. Although the reason for post anaesthesia temperature difference in the present experiments is uncertain, it may be associated with the reduced body weight and muscle wasting in the diabetic rats. If so, Meiri and McLean's finding that the velocity deficit was absent in the insulintreated diabetic rats could simply reflect prevention of muscle wasting by insulin.

Another way in which our data differ from those of Meiri and McLean is that our transport velocities are rather lower than in their controls and similar to the values for their diabetic rats. Other studies also give higher values for fast orthograde transport of proteins in sciatic motoneurones of non-diabetic rats, in the range of $410-430 \mathrm{~mm} /$ day $[11,12]$. We can, however, find nothing in our data to provoke suspicion of artefactually slow velocities. The small inter-animal variation is impressive, as is the agreement between control and diabetic groups at both survival times. Once again, we cannot rule out an influence of either the strain or sex of the experimental animals on axonal transport velocity. We have examined the possible influence of the anaesthetic and found similar velocities in control rats anaesthetised with halothane or with sodium methylhexitone. We have, however, used longer survival times than other workers in an attempt to avoid post anaesthetic hypothermia; it may be that in so doing we have discovered 
that velocity of transport decreases towards the extremities of the neurone. The position of our transport fronts at $6.5 \mathrm{~h}$ was $100 \mathrm{~mm}$ distal to the injection site compared with a maximum distance of about $80 \mathrm{~mm}$ in Meiri and McLean's work [5]. This effect may also be due to temperature difference, with the nerve becoming cooler as it becomes more superficial distal to the knee joint. Clearly this questions the validity of correlating nerve temperature measurements at mid-femur level with transport fronts which have progressed to a more distal point. However, we believe that attempts to measure nerve temperature distal to the knee joint would introduce artefacts.

The differences between the form of the transport profiles in Figure 1 raise the interesting possibility that diabetes may alter the identities or relative amounts of the proteins being transported in sciatic motoneurones. It is possible that the peak present in the nerves of the $4.5 \mathrm{~h}$ diabetic rats approximately $30 \mathrm{~mm}$ distal to the injection site indicates retardation of proteins which travelled at a faster velocity in the control rats. To determine whether or not this is a real phenomenon will require qualitative and quantitative analysis of the proteins.

Acknowledgements. This study was supported jointly by the British Diabetic Association (JT) and the Science and Engineering Research Council (SJW-C.A.S.E. scholar). Our thanks to Dr. W. G. McLean for teaching us the spinal cord injection technique. We thank Ms. H. Binks for typing this manuscript.

\section{References}

1. Perísíc M, Cuénod M (1972) Synaptic transmission depressed by colchicine blockade of axoplasmic flow. Science 175: 1140-1142
2. Sidenius P, Jakobsen J (1979) Axonal transport in early experimental diabetes. Brain Res 173: 315-330

3. Bisby MA (1980) Axonal transport of labelled protein and regeneration rate in nerves of streptozotocin diabetic rats. Exp Neurol 69: $74-84$

4. Bajada S, Sharma AK, Thomas PK (1980) Axoplasmic transport in vagal afferent fibres in normal and alloxan-diabetic rabbits. $J$ Neurol Sci 47:365-378

5. Meiri KF, McLean WG (1982) Axonal transport of protein in motor fibres of experimentally diabetic rats - fast anterograde transport. Brain Res 238: 77-88

6. Mendell JR, Sahenk Z, Warmolts JR, Marshall JK, Thibert P (1982) The spontaneously diabetic BB Wistar rat. Morphologic and physiologic studies of peripheral nerve. J Neurol Sci 52: 103-115

7. Bisby MA, Jones DL (1978) Temperature sensitivity of axonal transport in hibernating and non-hibernating rodents. Exp Neurol 61:74-83

8. Brimijoin S, Olsen J, Rosenson R (1979) Comparison of the temperature-dependence of rapid axonal transport and microtubules in nerves of the rabbit and bullfrog. J Physiol 287: 303-314

9. Brown AM, Slater EJ, Tomlinson DR (1985) Analysis of axonal transport of radiolabelled tracer molecules using a microcomputer. J Physiol 361: 10 P

10. Sokal RR, Rohlf FJ (1981) Biometry, 2nd edn. Freeman, New York, pp 226-227

11. Bisby MA (1976) Orthograde and retrograde axonal transport of labelled protein in motoneurones. Exp Neurol 50:628-640

12. Ochs S (1972) Rate of fast axoplasmic transport in mammalian nerve fibres. J Physiol 227:627-645

Received: 26 April 1985

and in revised form: 16 September 1985

Dr. David Tomlinson

Department of Physiology and Pharmacology

Medical School

Queen's Medical Centre

Nottingham NG7 2UH

UK 